\title{
Optimization of Process Parameters of Surface Roughness and Material Removal Rate in Orthogonal Turning of AISI 1045 Carbon Steel Using Taguchi Technique
}

\author{
EHIBOR, O. G. \& ALIEMEKE, B. N. G. \\ Department of Mechanical Engineering, Auchi Polytechnic, Auchi
}

\begin{abstract}
In today's manufacturing market, quality and productivity play significant role. This study is aimed at evaluating the best process environment which could simultaneously satisfy requirements of both quality and as well as productivity. This study investigates the effects of various parameters such as depth of cut, speed and feed on the material removal rate and surface roughness in a HMT (Hindustan Machine Tools) LB25 Lathe Machine. A plan of experiments based on Taguchi's technique has been used to acquire the data. An orthogonal array, the signal to noise $(\mathrm{S} / \mathrm{N})$ ratio and the analysis of variance (ANOVA) were employed to investigate the cutting characteristics of 1045 carbon steel using tungsten coated carbide cutting tool. The effectiveness of the predicted values with the experimental values in the analysis was carried out by confirmation tests. The analysis of results shows that the combination of process parameters for minimum surface roughness is obtained at $330 \mathrm{rpm}$ spindle speed, $0.2 \mathrm{~mm} / \mathrm{rev}$ feed and $0.6 \mathrm{~mm}$ depth of cut for minimum surface roughness. It is observed that feed rate plays an important role in minimizing surface roughness. For maximum material removal rate, the optimum values are spindle speed of $630 \mathrm{rpm}$, feed rate of $0.4 \mathrm{~mm} / \mathrm{rev}$ and depth of cut of $1.0 \mathrm{~mm}$. Finally, the relationship between cutting parameters and responses were developed by using the Minitab 18.1 software and regression equations were developed.
\end{abstract}

Keywords :Taguchi, ANOVA, Signal to Noise Ratio, Minitab and Surface Roughness.

DOI: $10.7176 /$ IEL/10-4-03

Publication date:May $31^{\text {st }} 2021$

\section{INTRODUCTION}

Machining is one of the most important and widely used manufacturing processes in engineering industry. Today's machining are caught between growing need for quality, high process safety, minimal machining costs, and short machining times. A manufacturing engineer or machine setup technician is often expected to utilize experience and published shop guidelines for determining the proper machining parameters to achieve a specified level of different response parameters. Therefore, in this situation, it is prudent for the engineer or technician to use past experience to select parameters which will likely yield an optimum response, and perhaps make some parameters adjustment as time allows or quality control requires. The rapid growth in manufacturing has created many economic, environmental and social problems from global warming to waste disposal (Sangwan, 2011).

Today, increasing the productivity and the quality of the machined parts in terms of workpieces dimensional accuracy, good surface finish, less tool wear on the cutting tools, high metal removal rate and economy of machining in terms of time per component, cost per component and the performance of the product are the main challenges of metal cutting industry during machining process(Das et al, 2012).

Conventional machines are usually controlled by hand wheels or levers. The machines take more time to make one component and needs one-man machine for supervision. This makes the manufactured product very costly as well as the quality of the product vary according to man expertise on that machine, which is not feasible in this competitive environment (Mohan \&Kiran 2017). Significant efforts have been devoted by several researchers in understanding and modeling of surface quality, metal removal rate which is a characteristic of machining time and cost (Rahul Davis et al. 2012), tool wear progression, wear mechanism, toll lifespan and cutting temperature in metal cutting. In recent years, a significant emphasis has placed in development of predictive models in metal cutting.

Due to the renewed interest in application of carbon steel because of its sustainability and $100 \%$ recyclable and almost indefinite life cycle, carbon steel is one of the most widely researched material in machining for more than last half a century (Sangwan, 2011). It is now the most common form of steel because of its relatively low prices while material of desirable properties acceptable for many applications are gotten from carbon steel. Carbon Steel mostly mild and medium carbon has a relatively low tensile strength, easy to form, malleable and ductile, they contain approximately $0.05-0.50 \%$ carbon. In applications where cross-sections are used for minimize deflection and where failure by yield is not a risk so carbon steels are the best choice, for example as structural steel. The density of carbon steel is approximately $7.85 \mathrm{~g} / \mathrm{cm}^{3}(7850 \mathrm{~kg} / \mathrm{m} 3$ or $0.284 \mathrm{Ib} / \mathrm{In} 3)$ and the 
Young's modulus is $200 \mathrm{GPa}(29000 \mathrm{ksi})$. Optimization is the selection of a best element with regards to some criterion from some set of available alternatives. It can also be define as the process of finding conditions that gives the minimum or maximum value of a function, where the function represent the effort required or the desired benefit (Romesh et al, 2017).

Most researches on machining show that the most widely considered machining performances by researchers are surface roughness, tool life, good cutting temperature followed by machining/production cost and material removal rate (Yusupet al, 2012). The focus of this study is to develop a statistical model for using the main cutting parameters of cutting speed, feed rate and depth of cut on 1045 carbon steel workpiece. Machining test will be carried out with coated carbide tipped cutting tool.

\section{LITERATURE REVIEW}

The 20th century ushered the developments of materials which allowed also new tools, new lathes and automatic machines, automatic control, ultra precision machining, computer integrated machining, milling and turning centers. Therefore, Automation in any company can help to reduce costs, decrease production cycle times, decrease the amount of manual tasks and increase process robustness and product quality (Sangwan, 2011).

Sandeep and Sunshil, (2014) investigated the optimization of cutting parameters (Cutting Speed, Feed Rate and Depth of Cut) for Surface Roughness in CNC turning of Mild Steel 1018 using Taguchi orthogonal design method and Analysis of Variance with the help of MINITAB 16 software with coated carbide cutting tool. Effect of cutting speed, feed rate and depth of cut on surface roughness was examined. Surface roughness increases when feed rate increases, however cutting speed also the influencing parameter followed by depth of cut.

Vipul\&Rajnikanr, (2017) optimized the process parameters during turning of AISI 1018 Low carbon steel with Cubic boron nitride cutting tool using Taguchi design of experiment methodology. Experimental tests were done based on L9 standard orthogonal array design with three process parameters namely cutting speed, feed rate, depth of cut for material removal rate and Machining time, the signal to noise ratio and analysis of variance (ANAVA) were employed to study the performance characteristics in turning operation. It was observed that the higher material removal rate will be at feed $0.20 \mathrm{~mm} / \mathrm{rev}$, speed $1700 \mathrm{RPM}$ and depth of cut $1.50 \mathrm{~mm}$ and from the ANOVA result, it was observed that the speed is the most influencing parameter for material removal rate. The lower Surface roughness was achieved at cutting speed $1300 \mathrm{RPM}$, feed $0.10 \mathrm{~mm} / \mathrm{rev}$ and depth of cut $0.75 \mathrm{~mm}$

Romesh et al, (2017) performed the effect of Process Parameters and Optimization of MRR in Turning of EN8 Steel on CNC Lathe using Response Surface Methodology. From the experimental tests carried out, the cutting speed, depth of cut and feed rate, all found to have contributed in obtaining maximum MRR but depth of cut is the most significant factor. Using regression analysis, the evaluation of the mathematical model shows that the predicted values are much closer to experimental values and the percentage error for the optimum MRR is minimum. RSM has been applied to optimize the results. The optimum set of parameters are cutting speed 1200 $\mathrm{rpm}$, depth of cut $-0.3 \&$ feed rate $-0.25 \mathrm{~mm} / \mathrm{rev}$, and the optimum value of MRR is $5476.16 \mathrm{~mm}^{3} / \mathrm{min}^{\text {. their }}$ contribution factor depth of cut $(72.64 \%)$, cutting speed is $(32.84 \%)$ while feed rate has insignificant effect on MRR.

Kpina andNwosu, (2018) carried out an experimental study of roughness characteristics of surface profile generated in turning of AISI 1040 Mild Steel using NAG=MATI175 lathe machine. The study aimed at modeling of machining parameters in turning operation to enhance surface quality. Machining was done using high speed steel under dry cutting condition. The machining parameters were the spindle speed, the feed rate; the L27 orthogonal array was selected. A multiple regression model was developed to study the effect of cutting parameters on surface quality/roughness. The prediction ability of the model was tested and analysis of variance(ANOVA) was carried out. From the experimental test, the results reveals that the combination that gives the optimum condition of better surface finish are the feed rate of level $1(0.10 \mathrm{~mm} / \mathrm{rev}$, spindle speed of level $3(900 \mathrm{rpm})$, depth of cut at level $1(0.5 \mathrm{~mm})$ and nose radius at level $1(0.6 \mathrm{~mm})$. in addition, the author recommends that further study could be possible considering other factors such as the use of cutting fluid, the effects of coolant systems on turning operation maybe considered for better quality of machined surface.

Mgbemena et al, (2016) carried out a study on AISI 1018 carbon steel during turning operation to reduce tooling costs as a result of tool wear and achieve optimum metal removal rate. Taguchi technique was employed using the L9 orthogonal array and the analysis of variance (ANOVA) to investigate the effect of the turning parameters on Metal Removal Rate (MRR) and Tool Wear Rate (TWR). The results revealed that depth of cut is the most significant process parameter for MRR with a percentage contribution of $86.84 \%$; for the metal removal rate, the optimal machining condition was obtained at a cutting speed of $140 \mathrm{rpm}$, a feed of $0.30 \mathrm{~mm} / \mathrm{rev}$ and a depth of $0.75 \mathrm{~mm}$. The cutting speed and the feed rate are the most significant process parameters for TWR with percentage contributions of $60.86 \%$ and $30.03 \%$ respectively. For the tool wear rate, the optimal machining condition was obtained at a cutting speed of $140 \mathrm{rpm}$, a feed of $0.30 \mathrm{~mm} / \mathrm{rev}$ and a depth of $0.75 \mathrm{~mm}$. The study concludes that AISI 1018 low carbon steel has a maximum MRR of $35.29 \mathrm{~mm}^{3} / \mathrm{s}$ and a minimum TWR of 


\section{$0.21 \mathrm{~mm} / \mathrm{s}$.}

Modeling and Optimization require selection of appropriate sets of machining parameters of the process and can mainly be achieved by understanding the interrelationship among the large numbers of parameters affecting the process and identifying the optimal machining conditions. Experiments will be performed on a given machine tool in order to understand the effect of different process parameters on performance characteristics.

The aim of this research is the optimization of process parameters of surface roughness and material removal rate in orthogonal turning of AISI 1045 Carbon Steel using Taguchi technique. This aim will be achieved through the following objectives:

i. To carry out machining of 1045 Carbon Steel using design of Experiment (DOE) via Taguchi.

ii. To develop empirical models for prediction of machining quality characteristic for minimum surface roughness and maximum materials removal rate.

iii. To find out which process parameters is more or less significant in influencing the response parameters using the Analysis of Variance (ANOVA).

iv. Generation of Regression equations used to find the optimum surface roughness and material removal rate at any cutting parameters.

\section{Material and Method}

The sample material; for this research is a 1045 Carbon Steel. There is a renewed interest in the application of carbon steel because of its sustainability. It is $100 \%$ recyclable and almost has indefinite life cycle. This steel is one of the steel grades widely used in different industries like construction, transport, structural designs, automotive, power and so on.Material removal rate is a function of productivity and increase in productivity is desired during machining processes(Muley et al, 2016). The chemical composition and mechanical properties of this steel are given below. A total of nine experiments will be performed according to the experimental design. The length of cut for each run is $400 \mathrm{~mm}$ with $100 \mathrm{~mm}$ length provided for clamping the work piece into the chuck of the lathe. Each piece is $500 \mathrm{~mm}$ length and $50 \mathrm{~mm}$ diameter and will be used to perform three experiments. A pre-cut of $0.5 \mathrm{~mm}$ depth will be performed on each work piece using a different cutting tool. This will be done in order to remove the rust or hardened top layer from the surface and to minimize any effect of non-homogeneity on the experimental result. The investigation will be carried out using a HMT (Hindustan Machine Tool) LB25 lathe machine with a tungsten coated carbide cutting tool insert. The chemical composition of the selected work piece from the spectrographic test carried out and some of the mechanical properties test carried out in the materials laboratory are shown in the tables below.

Table 1: Chemical composition of AISI 1045 steel in percentage weight

\begin{tabular}{|l|l|l|l|l|l|}
\hline Material & Carbon (\%) & Manganese (\%) & Phosphorus (\%) & Sulphur (\%) & Silicon (\%) \\
\hline AISI 1045 Carbon Steel & 0.45 & 0.75 & 0.04 & 0.05 & 0.16 \\
\hline
\end{tabular}

Table 2: Mechanical properties of AISI 1045 steel

\begin{tabular}{|l|l|l|l|l|l|l|l|}
\hline Material & $\begin{array}{l}\text { Density } \\
\mathbf{( k g / m 3 )}\end{array}$ & $\begin{array}{l}\text { Elastic } \\
\text { Modulus } \\
(\mathbf{G P a})\end{array}$ & $\begin{array}{l}\text { Yield } \\
\text { Strength } \\
(\mathbf{M P a})\end{array}$ & $\begin{array}{l}\text { Tensile } \\
\text { Strength } \\
(\mathbf{M P a})\end{array}$ & $\begin{array}{l}\text { Hardness } \\
\mathbf{( H B )}\end{array}$ & $\begin{array}{l}\text { Elongation } \\
\mathbf{( \% )}\end{array}$ & $\begin{array}{l}\text { Poison } \\
\text { Ratio }\end{array}$ \\
\hline $\begin{array}{l}\text { AISI 1045 } \\
\text { Carbon Steel }\end{array}$ & 7.8 & 205 & 505 & 585 & 170 & 16 & 0.29 \\
\hline
\end{tabular}

Cutting speed, feed rate and depth of cut were selected as the machining parameters to analyze their effect on surface roughness and material removal rate as well. The choice of machining parameters was made by taking into account the capacity/limiting cutting conditions of the lathe, tool manufacturer's catalogue and the values taken by researchers in the literature. Cutting speed (v), feed rate (f) and depth of cut $(d)$ were chosen as the input parameters for this research. A total of 9 experiments based on Taguchi's L $9\left(3^{3}\right)$ orthogonal array were carried out with different combinations of the levels of the input parameters. The following three Spindle speeds 150, 330 and $630 \mathrm{rpm}$ are available in the HMT LB25 lathe machine and hence are selected as levels. A higher spindle speed was avoided due to vibration problems. 


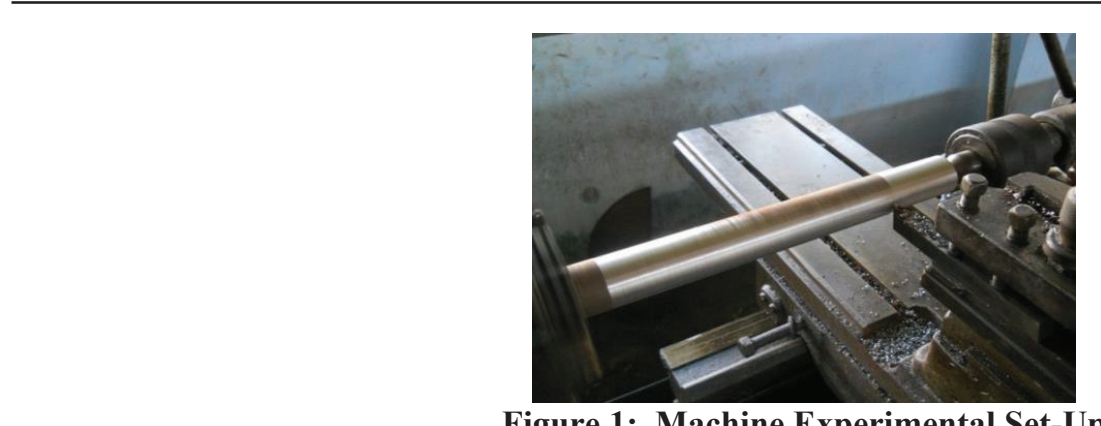

Figure 1: Machine Experimental Set-Up

\subsection{Cutting Tool Inserts and Holder}

Coated carbide cutting tools will be used for this experiment. This cutting tool to be use is proper for machining of 1045 carbon steel. Inserts of ISO TNMG designation having $0.4 \mathrm{~mm}$ nose radius was mounted on the tool holder. For this reason, the selection of the right cutting tool geometry is important in metal cutting (Harinath et al, 2014). An insert mounted on the tool holder is shown below in Figure 2.

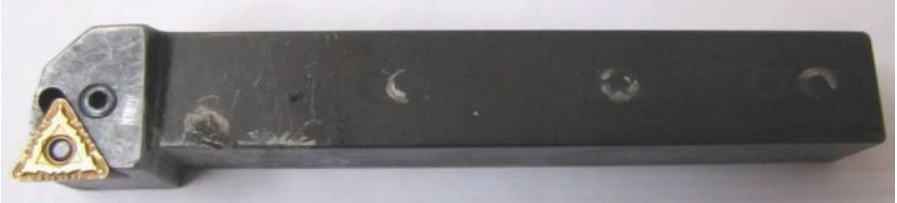

Figure 2: Insert mounted on the tool holder.

\subsection{Machine Tool}

The turning experiments were carried out using an HMT Centre Lathe. The work piece was held between chuck and tailstock; and the tool overhang was kept to increase rigidity of the machining system as shown in figure 3 below:

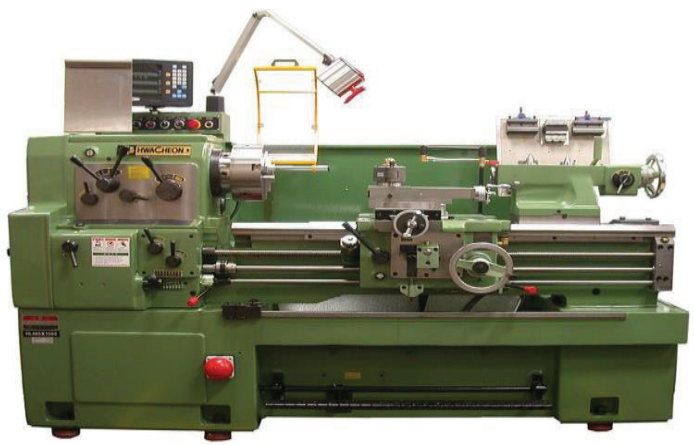

Figure 3: HMT Centre Lathe.

Cutting speed (v), feed rate (f) and depth of cut $(d)$ are the input parameters chosen for the research. The performance characteristics chosen to investigate the effect of machining parameters were surface roughness (Ra) and the material removal rate (MRR).

\section{Table 3: Experimental Conditions}

\begin{tabular}{|l|l|}
\hline Work piece material & 1045 Carbon Steel \\
\hline Length of work piece & $500 \mathrm{~mm}$ (Machined Length $=400 \mathrm{~mm})$ \\
\hline Diameter of work piece & $50 \mathrm{~mm}(49.5 \mathrm{~mm}$ after pre-cut) \\
\hline Lathe used & HMT Centre Lathe \\
\hline Surface Tester & Mitutoyo(SJ-210 ISAO 1997) portable surface tester \\
\hline Cutting Tool Used & Coated Cemented Carbide Cutting Tool \\
\hline
\end{tabular}

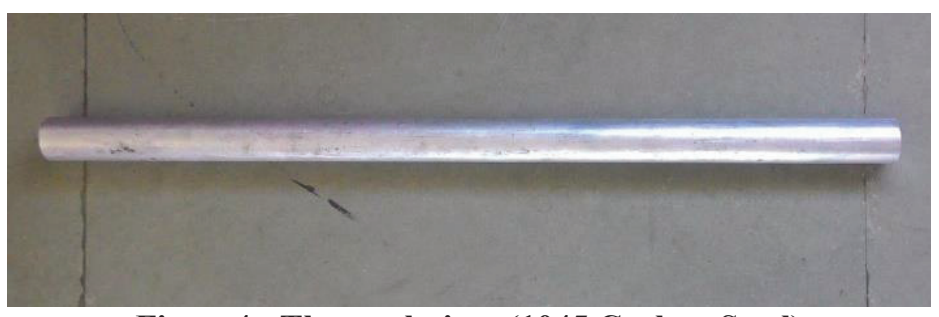

Figure4 : The workpiece (1045 Carbon Steel) 


\subsection{Experimental Design}

The experiments are performed on the HMT Centre Lathe. The tool and material selected were coated carbide tool and carbon steel respectively. Three process parameters, as already stated above, cutting speed (A), Feed rate (B) and Depth of cut (C) were considered in the study. Three levels of cutting speed, feed and depth of cut were used and are shown in the Table 4 below. Three lengths of 500 $\mathrm{mm}$ length of the work piece were available, three runs were carried out on each work piece and the length of cut for each run was $400 \mathrm{~m}$.

Table 4: Process parameters with their values at 3 levels

\begin{tabular}{|l|l|l|l|l|}
\hline Factors & Symbols & Level 1 & Level 2 & Level 3 \\
\hline Spindle Speed (rpm) & V & 150 & 330 & 630 \\
\hline Feed Rate (mm/rev) & F & 0.2 & 0.3 & 0.4 \\
\hline Depth of Cut (mm) & D & 0.6 & 0.8 & 1.0 \\
\hline
\end{tabular}

\subsection{Determination of Surface Roughness}

Surface finish is an essential requirement in determining the surface quality of a product and also is often a good predictor of the quality for cracks or corrosion. Roughness is a measure of the texture of a surface. It is qualified by the vertical deviations of a real surface from its ideal form. Surface roughness (Ra) was considered as output parameter and it was measured using a tester (Model - Mitutoyo SJ-210 ISO 1997) portable surface roughness tester at three different points of the machined work piece.

\subsection{Determination of Material Removal Rate}

The metal removal rate (MRR) in turning operations is the volume of material/metal that is removed per unit time in $\mathrm{mm}^{3} / \mathrm{min}$. for each revolution of the work piece, a ring shaped layer of material is removed.

The following are the derivation of important machining parameters (Yanda et al, 2010).

\subsection{Spindle Speed (V)}

From figure 5 below, the equation of spindle speed $(\mathrm{N})$ to achieve cutting speed can be expressed as shown below in equation of spindle speed to achieve a specific cutting speed can be expressed as shown below in Eq. (1)

$N=k, \quad \frac{v}{\pi D_{1}}$

If $\mathrm{N}$ is spindle speed in revolutions/ minutes (rpm), $\mathrm{k}$ is a constant to correct the cutting speed (v) and $\mathrm{v}$ is the desired cutting speed, and D1 is the largest part diameters (initial size). The value of a constant of $\mathrm{k}$ depends on the unit choice of the cutting speed (v), which is given in meters per minutes $(\mathrm{m} / \mathrm{min})$ and $\mathrm{D}_{1}$ in $\mathrm{mm}: \mathrm{k}=1000$ (Yanda et al, 2010).

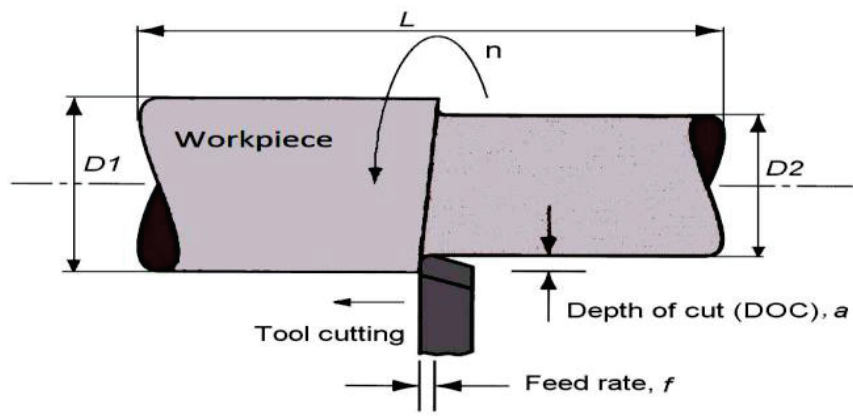

Figure 5: Schematic diagram of the orthogonal metal cutting configuration (Yanda et al, 2010)

Therefore, If cutting speed in $\mathrm{m} / \mathrm{min}$ for a given $\mathrm{rpm}$ rate is desired, $\mathrm{k}=1000$, solve above equation for cutting speed $(V)$ now becomes:

$V=\frac{\pi d n}{1000}$

\subsection{Cutting Time (CT)}

Cutting time for a length of work piece (L) is as shown in Eq. (3) below:

$C T=\frac{(L+A)}{f \times n}$

Where CT is cutting time in min, $L$ is length of cut in $\mathrm{mm}, A$ is allowance or starting offset in $\mathrm{mm}^{2}$, fis feed rate 
in $\mathrm{mm} /$ revolution.

Therefore, Materials Removal Rate for Turning, MRR,

$\mathrm{MRR}=$ Volume Removed $/$ Cutting Time.

$M R R=\pi L \frac{\left(D_{1}^{2}-D_{2}^{2}\right)}{(4 L / f n)}$

If $\mathrm{D}_{1}$ and $\mathrm{D}_{2}$ are the diameters of workpiece before and after machining, $\mathrm{L}$ is length of machined workpiece, $\mathrm{f}$ is the feed rate, $\mathrm{N}$ is the Spindle Speed in rpm and a is the depth of cut in mm (Muley et al, 2016).

$$
\begin{aligned}
& M R R=\pi L\left(D_{1}^{2}-D_{2}^{2}\right) *(f n / 4 L) \\
& M R R=\frac{\pi}{4}\left(D_{1}^{2}-D_{1}^{2}\right) * f n \\
& M R R=0.7855\left(D_{1}^{2}-D_{2}^{2}\right) * f n
\end{aligned}
$$

Where D1 and D2 are the initial and final diameter of the workpiece before and after turning, $\mathrm{f}$ is the feed and $\mathrm{N}$ is the spindle speed in rpm (Muley et al, 2016).

\begin{tabular}{|c|c|c|c|c|c|c|c|c|}
\hline \multirow[t]{2}{*}{ S/NO } & \multirow{2}{*}{$\begin{array}{l}\text { SPINDLE } \\
\text { SPEED } \\
(\text { rpm) }\end{array}$} & \multirow{2}{*}{$\begin{array}{l}\text { FEED } \\
\text { RATE } \\
(\mathrm{mm} / \mathrm{rev})\end{array}$} & \multirow{2}{*}{$\begin{array}{l}\text { DEPTH } \\
\text { OF CUT } \\
(\mathrm{mm})\end{array}$} & \multicolumn{3}{|c|}{ SRFACE R. (Ra) $\mu m$} & \multirow{2}{*}{$\begin{array}{l}\text { AVERAGE } \\
-(\mathrm{Ra}) \boldsymbol{\mu m}\end{array}$} & \multirow{2}{*}{$\begin{array}{l}\text { MRR } \\
\mathrm{mm} / \mathrm{min}\end{array}$} \\
\hline & & & & RUN 1 & RUN2 & RUN3 & & \\
\hline 1 & 150 & 0.2 & 0.6 & 2.119 & 2.125 & 2.107 & 2.117 & 2992.99 \\
\hline 2 & 150 & 0.3 & 0.8 & 2.691 & 2.703 & 2.722 & 2.705 & 5031.72 \\
\hline 3. & 150 & 0.4 & 1.0 & 3.675 & 3.671 & 3.676 & 3.674 & 13456.09 \\
\hline 4. & 330 & 0.2 & 0.8 & 1.440 & 1.560 & 1.350 & 1.450 & 6084.29 \\
\hline 5. & 330 & 0.3 & 1.0 & 2.284 & 2.268 & 2.273 & 2.275 & 14713.04 \\
\hline 6. & 330 & 0.4 & 0.6 & 2.974 & 2.970 & 2.978 & 2.974 & 12306.49 \\
\hline 7. & 630 & 0.2 & 1.0 & 1.884 & 1.768 & 1.943 & 1.865 & 18258.54 \\
\hline 8. & 630 & 0.3 & 0.6 & 1.962 & 1.842 & 2.058 & 1.954 & 15367.04 \\
\hline 9. & 630 & 0.4 & 0.8 & 2.938 & 2.724 & 2.873 & 2.845 & 30723.20 \\
\hline
\end{tabular}

\subsection{RESULT AND ANALYSIS}

Table 5: data from the Experiment conducted

Table 6: Surface Roughness Characteristics

\begin{tabular}{|l|l|l|l|l|c|}
\hline $\begin{array}{l}\text { Experimental } \\
\text { Number }\end{array}$ & $\begin{array}{l}\text { Spindle Speed } \\
(\mathbf{r p m})\end{array}$ & $\begin{array}{l}\text { Feed Rate } \\
(\mathbf{m m} / \mathbf{r e v})\end{array}$ & $\begin{array}{l}\text { Depth of } \\
\text { Cut }(\mathbf{m m})\end{array}$ & $\begin{array}{l}\text { SRFACE } \\
\text { roughness, } \\
(\text { Ra) } \boldsymbol{\mu m}\end{array}$ & $\begin{array}{l}\text { S/N ratio of } \\
\text { surfaces roughness }\end{array}$ \\
\hline 1 & 150 & 0.3 & 0.6 & 2.117 & -6.51442 \\
\hline 2 & 150 & 0.2 & 0.8 & 2.705 & -8.64335 \\
\hline 3. & 150 & 0.4 & 1.0 & 3.674 & -11.3028 \\
\hline 4. & 330 & 0.2 & 0.8 & 1.45 & -3.22736 \\
\hline 5. & 330 & 0.3 & 1.0 & 2.274 & -7.13963 \\
\hline 6. & 330 & 0.4 & 0.6 & 2.974 & -9.46682 \\
\hline 7. & 630 & 0.2 & 1.0 & 1.865 & -5.41358 \\
\hline 8. & 630 & 0.3 & 0.6 & 1.954 & -5.81849 \\
\hline 9. & 630 & 0.4 & 0.8 & 2.845 & -9.08165 \\
\hline
\end{tabular}

Table. 7: Response Table for Signal to Noise Ratios (Surface Roughness).

Smaller is better

\begin{tabular}{lllr} 
LEVEL SPEED & FEED & DEPTH & \\
\hline 1 & -8.82 & -5.052 & -7.267 \\
2 & -6.611 & -7.2 & -6.984 \\
3 & -6.771 & -9.95 & -7.952 \\
Delta & 2.209 & 4.899 & 0.968 \\
Rank & 2 & 1 & 3
\end{tabular}


Table 8: Material Removal Rate (MRR)

\begin{tabular}{|l|l|l|l|l|l|}
\hline $\begin{array}{l}\text { Experimental } \\
\text { Number }\end{array}$ & $\begin{array}{l}\text { Spindle Speed } \\
(\mathbf{r p m}) \mathbf{N}\end{array}$ & $\begin{array}{l}\text { Feed Rate } \\
(\mathbf{m m} / \mathbf{r e v})\end{array}$ & $\begin{array}{l}\text { Depth of cut } \\
(\mathbf{m m})\end{array}$ & $\begin{array}{l}\text { Material } \\
\text { Removal Rate } \\
\left(\mathbf{m m}^{3} / \mathbf{m i n}\right)\end{array}$ & $\begin{array}{l}\text { S/N ratio of } \\
\text { MRR }\end{array}$ \\
\hline 1 & 150 & 0.2 & 0.6 & 2992.99 & 69.52211 \\
\hline 2 & 150 & 0.3 & 0.8 & 5031.72 & 74.03433 \\
\hline 3. & 150 & 0.4 & 1.0 & 13456.09 & 82.57838 \\
\hline 4. & 330 & 0.2 & 0.8 & 6084.29 & 75.6842 \\
\hline 5. & 330 & 0.3 & 1.0 & 14713.04 & 83.35405 \\
\hline 6. & 330 & 0.4 & 0.6 & 12306.49 & 81.80268 \\
\hline 7. & 630 & 0.2 & 1.0 & 18258.54 & 85.22932 \\
\hline 8. & 630 & 0.3 & 0.6 & 15367.04 & 83.7318 \\
\hline 9. & 630 & 0.4 & 0.8 & 30723.20 & 89.74933 \\
\hline
\end{tabular}

Table. 9: Response Table for Signal to Noise Ratios for Material Removal Rate.

Larger is better

\begin{tabular}{lcrr} 
Level & SPEED FEED & \multicolumn{2}{c}{ DEPTH } \\
\hline 1 & 75.38 & 76.81 & 78.35 \\
2 & $\mathbf{8 0 . 2 8}$ & 80.37 & 79.82 \\
3 & 86.24 & 84.71 & 83.72 \\
Delta & 10.86 & 7.90 & 5.37 \\
Rank & 1 & 2 & 3
\end{tabular}

\subsection{Main Effect Plots}

The main effect plots of signal-to-noise ratio (S/N Ratio) as shown in the Fig. 6 and Fig. 7 was used to determine the optimum values for each parameter during the turning process for the surface roughness and material removal rate.

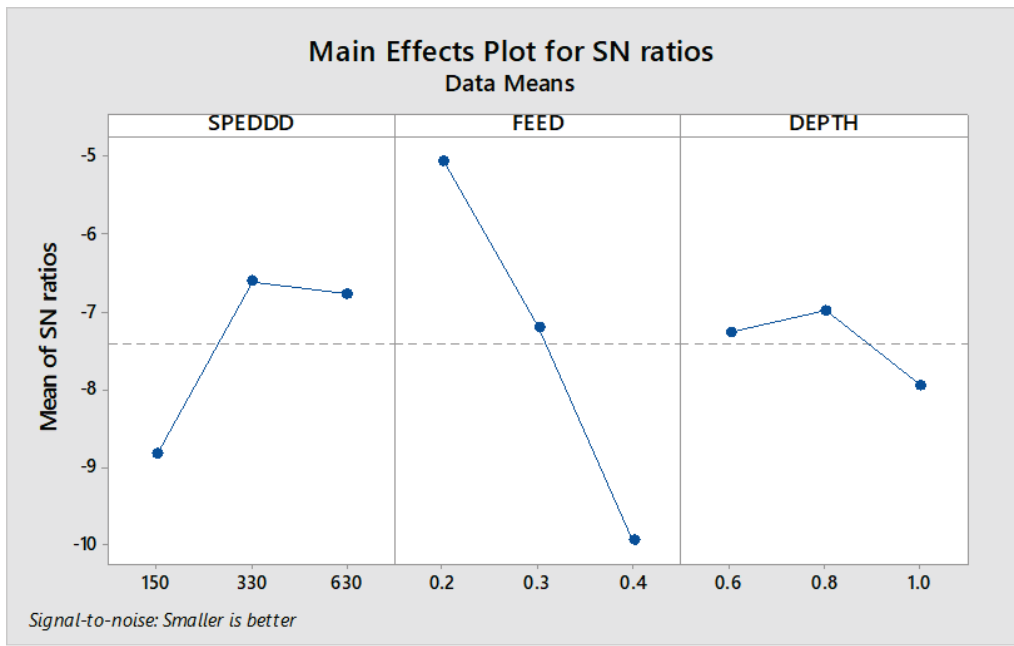

Fig 6: Main effects plot for $\mathrm{S} / \mathrm{N}$ ratios for surface roughness 


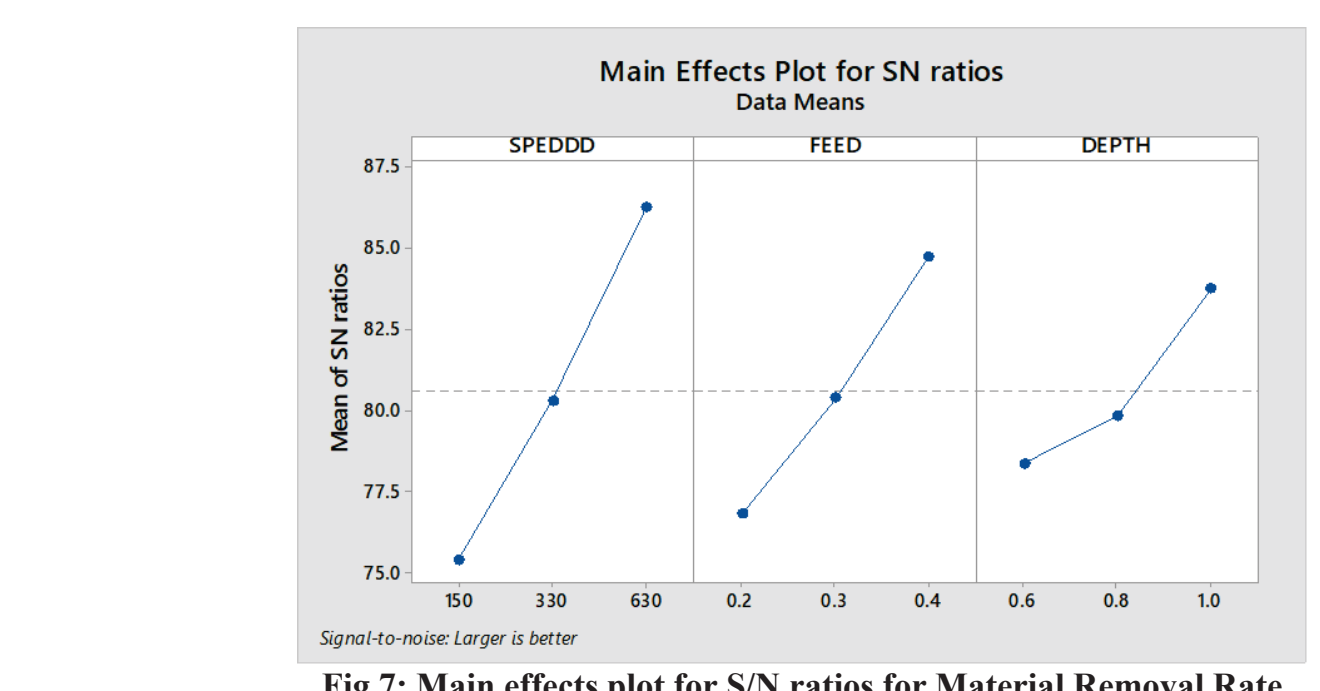

Fig 7: Main effects plot for $\mathbf{S} / \mathbf{N}$ ratios for Material Removal Rate

The lower the better characteristic was chosen for the surface roughness while the larger the better was chosen for the material removal rate responses. Here, the optimal turning parameters for the surface roughness in (Fig 6) are $330 \mathrm{rpm}$ of spindle speed (level 2), $0.2 \mathrm{~mm} / \mathrm{rev}$ of feed (level 1) and $0.8 \mathrm{~mm}$ of depth of cut (level 2) while for the material removal rate (Fig 7) are $630 \mathrm{rpm}$ of spindle speed (level 3), $0.4 \mathrm{~mm} / \mathrm{rev}$ of feed rate (level 3) and $1.0 \mathrm{~mm}$ of depth of cut (level 3 ).

\subsection{Signal to Noise Ratio}

In Taguchi design, parameters that have an effect on the output are often divided into 2 parts: governable (or design) factors and uncontrollable (or noise) factors. The term 'signal' represents the desirable value (mean) for the output characteristic and the term 'noise' represents the undesirable value for the output characteristic. S/N ratio is used to measure the quality characteristic deviating from the desired value. Smaller-the-Better is employed for surface roughness and Larger-the-Better is employed for material removal rate. As a result, we tend to minimize the surface roughness and maximize the material removal rate.

\subsection{ANOVA for Surface Roughness}

Results obtained for the surface roughness area unit shown above. The results for surface roughness were obtained from the nine experiments performed of Taguchi. The experimental results analyzed as shown in the table 10 below. MINITAB 18.1 software was used. The importance of the factors on the required characteristics was shown in the ANOVA table. The results show that solely feed is that the most important factor.

\subsection{ANOVA Analysis}

ANOVA statistics as shown in Tables 10 and 11 was used to study the significance of the input parameters on the surface roughness and the material removal rate.

Table 10:Analysis of Variance for SN ratios for Surface Roughness.

\begin{tabular}{lllllll} 
Factors & DF & Seq SS & Adj SS & Adj MS & F & P \\
\hline Spindle Speed & 2 & 9.103 & 9.103 & 4.5515 & 5 & 0.167 \\
Feed Rate & 2 & 36.176 & 36.176 & 18.0878 & 19.85 & 0.048 \\
Depth of Cut & 2 & 1.486 & 1.486 & 0.7432 & 0.82 & 0.551 \\
Residual Error & 2 & 1.822 & 1.822 & 0.9111 & & \\
Total & 8 & 48.587 & & & &
\end{tabular}

As shown in the Table 10 above, the significant effects of cutting speed, feed rate and depth of cut on the surface roughness are as follows: cutting speed (18.7\%), feed (74.46\%) and depth of cut (3.06\%). These results show that the feed rate has the most significant influence or impact on the surface roughness, followed by the cutting speed. This indicated that the feed rate, distantly followed by the cutting speed is more significant than the depth of cut on the surface roughness during this machining operation. 


\subsection{Regression Equation for Surface Roughness}

Surface Roughness

$$
\begin{aligned}
& =0.310-0.001146 \text { Spindle speed }+6,77 \text { Feed rate } \\
& +0.641 \text { Depth of cut }
\end{aligned}
$$

Regression equation is used to find the optimum surface roughness at any cutting parameters. We can apply this equation for optimum values for surface roughness. Regression analysis has been performed to find out the relationship between input factors and Surface Roughness. During regression analysis it was assumed that the factors and the response are linearly related to each other by the equation above.

Table 11:Analysis of Variance for SN ratios for Material Removal Rate.

\begin{tabular}{lllllll} 
Factors & DF & Seq SS & Adj SS & Adj MS & F & P \\
\hline Spindle Speed & 2 & 177.418 & 177.418 & 88.709 & 432.67 & 0.002 \\
Feed Rate & 2 & 93.874 & 93.874 & 46.9371 & 228.93 & 0.004 \\
Depth of Cut & 2 & 46.176 & 46.176 & 23.0879 & 112.61 & 0.009 \\
Residual Error & 2 & 0.41 & 0.41 & 0.205 & & \\
Total & 8 & 317.878 & & & &
\end{tabular}

As shown in the Table 11 above, the significant effects of the cutting speed, feed rate and the depth of cut on the material removal rate are as follows: $55.81 \%$ for cutting speed, $29.53 \%$ for the feed rate and $14.53 \%$ for the depth of cut. It shows that cutting speed (55.81\%) followed by the feed $(29.53 \%)$ have the most significant influence on the material removal rate during this machining process.

\subsection{Regression Equation for Material Removal Rate.}

Regression analysis has been performed to find out the relationship between input factors and MRR. During regression analysis it was assumed that the factors and the response are linearly related to each other.

\section{Material Removal Rate}

$$
\begin{aligned}
& =-23069+30.27 \text { Spindle speed }+48583 \text { Feed rate } \\
& +13134 \text { Depthof cut }
\end{aligned}
$$

Regression equation is used to find the optimum MRR at any cutting parameters. We can apply this equation for optimum values for MRR. The positive value of spindle speed, feed rate and depth of cut is indicative that increase in process parameters increases the material removal rate.

\subsection{Conclusion}

The Surface roughness is principally plagued by feed rate, depth of cut and spindle speed. With the rise in feedrate the surface roughness increases. The parameters taken within the experiments area unit optimized to get the minimum surface roughness potential.

The optimum setting of cutting parameters for high quality turned workpiece is as:-

1. Spindle Speed $=330 \mathrm{rpm}$ (Second Level) 2. Feed Rate $=0.2 \mathrm{~mm} / \mathrm{rev}($ First Level)

3. Depth of Cut $=0.6 \mathrm{~mm}$ (Second Level)

The parameters taken within the experiments area unit optimizedto realize most material removal rate potential. The simplest setting of input method parameters for defect-free turning (maximum material removal rate) are as follows:-

1. Spindle speed $=630 \mathrm{rpm}($ Third Level) $\quad$ 2. Feed rate $=0.4 \mathrm{~mm} / \mathrm{rev}($ Third Level $)$

3. Depth of cut $=1.0 \mathrm{~mm}$ (Third Level)

\subsection{RECOMMENDATIONS}

In this present study solely three input (operating) parameters which are the spindle speed, the feed rate and the depth of cut are studied in accordance with their effects. Alternative factors like tool radius, types of Inserts, cutting conditions (dry or wet) should also be explored and be studied. Also, other output parameters like power consumption, cutting forces, cutting temperature, tool life etc. could also be optimized for the overall best economy of machining.

\subsection{Conflict of Interest}

The authors of this article have not declared any conflict of interest.

\subsection{Acknowledgement}

The authors of this article would like to appreciates the management of Tertiary Education Trust Fund 
(TETFund) Abuja and Auchi Polytechnic, Auchi for providing the needed fund for this noble research. This type of collaboration and assistance is necessary for sustainable development at the tertiary education level in Nigeria

\section{REFERENCES}

Das, S. R., Nayak, R. P., \&Dhupal, D. (2012). Optimization of Cutting Parameters On Tool Wear And Workpiece Surface Temperature In Turning Of Aisi D2 Steel. International journal of lean thinking, 3(2), 140-156.

HarinathGowd G., Venugopal G. M., Divya T. K. \& Reddy M. G. (2014), “Optimal Selection of Machining Parameters in CNC Turning Process of EN-31 Using Intelligent Hybrid Decision Making Tools", 12th Global Congress on Manufacturing and Management, Procedia Engineering 97, pp. 125 - 133.

Kpina, B. Charles \&Nwosu H. U., (2018) "Modelling of Cutting Parameters in Turning Operation to Enhance Surface Quality" International Journal of Recent Engineering Science (IJRES), Volume 5 Issue 3.

Mgbemena, C., Etebenumeh, G., Ashiedu, F. (2016).Effect of turning parameters on Metal Removal and Tool Wear rates of AISI 1018 Low Carbon Steel.Nigerian Journal of Technology (NIJOTECH).Vol. 35, No. 4, pp. $847-854$

Mohan Kumar S., andKiran Kumar K. (2017). “Optimization Techniques in Turning Operation by using Taguchi Method"International Journal of Engineering and Advanced Technology (IJEAT)ISSN: 2249 - 8958, Volume-6 Issue-6.

Muley, R.A., Ulkarni, A.R.K., Deshmukh, R.R. (2016) "Optimization of Surface Roughness and Material Removal Rate in Turning of AISI D2" International Journal of Mechanical And Production Engineering, Volume- 4, Issue-7,

Rahul Davis \& Mohamed Alazhari (2012) "Analysis and Optimization of Surface Roughness in Dry Turning Operation of Mild Steel" International Journal of Industrial Engineering Research and Development Volume 3, Issue 2, pp. 01-09.

Romesh, V; Pavan A; Mittal P. (2017); "Effect of Process Parameters and Optimization of MRR in Turning of EN8 Steel on CNC Lathe using Response Surface Methodology" International Journal for Research in Applied Science \& Engineering Technology (IJRASET), 5, VIII, 1008 - 1024.

Sandeep Kumar \&Sushil Kumar S. (2014), Optimization of Material Removal Rate in CNC Turning of Mild Steel 1018 Using Taguchi Method.Int. Journal of Engineering Research and Applications, Vol. 4, Issue 4( Version 5), pp.69-73

Sangwan K. Singh, (2011). Development of a multi criteria decision model for justification of green manufacturing systems. Green Econ. 5, 285-305.

Vipul V. \&Rajnikanr B., (2017) "Optimization of Process Parameters in Turning Operationof AISI-1018 with Carbon boron nitride cutting tool Using Taguchi Method And ANOVA." International Archive of Applied Sciences and Technology Int. Arch. App. Sci. Technol; Vol 8 [3] pp 47-52

Yanda H., Ghani J. A., RodziM. N. A. N., Othman K. \&Haron C. H. C. (2010) "Optimization of Material Removal Rate, Surface Roughness and Tool Life on Conventional dry Turning of FCD700". International Journal of Mechanical and Materials Engineering (IJMME), Vol.5, No.2, pp182-190.

Yusup, N., Mohd, A., Zaiton, S., Hashirn, M., (2012). Expert Systems with Applications Evolutionary techniques in optimizing machining parameters: Review and recent applications (2007-2011). Expert Syst. Appi.39, 9909-9927. 